\title{
Lake surface temperatures in a changing climate: a global sensitivity analysis
}

\author{
Martin Schmid • Stefan Hunziker • Alfred Wüest
}

Received: 27 June 2013 / Accepted: 7 February 2014 / Published online: 5 March 2014

(C) Springer Science+Business Media Dordrecht 2014

\begin{abstract}
We estimate the effects of climatic changes, as predicted by six climate models, on lake surface temperatures on a global scale, using the lake surface equilibrium temperature as a proxy. We evaluate interactions between different forcing variables, the sensitivity of lake surface temperatures to these variables, as well as differences between climate zones. Lake surface equilibrium temperatures are predicted to increase by 70 to $85 \%$ of the increase in air temperatures. On average, air temperature is the main driver for changes in lake surface temperatures, and its effect is reduced by $\sim 10 \%$ by changes in other meteorological variables. However, the contribution of these other variables to the variance is $\sim 40 \%$ of that of air temperature, and their effects can be important at specific locations. The warming increases the importance of longwave radiation and evaporation for the lake surface heat balance compared to shortwave radiation and convective heat fluxes. We discuss the consequences of our findings for the design and evaluation of different types of studies on climate change effects on lakes.
\end{abstract}

\section{Introduction}

The most direct effect of climate change on lakes is a warming of the lake surface temperature $\left(T_{\text {surf }}\right)$. Warming trends of $T_{\text {surf }}$ mostly between 0.01 and $0.1^{\circ} \mathrm{C} \mathrm{yr}{ }^{-1}$ have been observed in the last decades both in-situ (Shimoda et al. 2011), and from satellites, with a spatial distribution

Electronic supplementary material The online version of this article (doi:10.1007/s10584-014-1087-2) contains supplementary material, which is available to authorized users.

M. Schmid $(\bowtie) \cdot$ S. Hunziker $\cdot$ A. Wüest

Surface Waters - Research and Management, Eawag, Swiss Federal Institute of Aquatic Science and Technology, Eawag, Seestrasse 79, CH-6047 Kastanienbaum, Switzerland e-mail: martin.schmid@eawag.ch

S. Hunziker

Department of Geography, University of Zurich, Zurich, Switzerland

S. Hunziker

Institute of Geography and Oeschger Centre for Climate Change Research, University of Bern, Bern, Switzerland

A. Wüest

Physics of Aquatic Systems Laboratory, Margaretha Kamprad Chair, EPFL, ENAC-IIE-APHYS, Lausanne, Switzerland 
similar to air temperature $\left(T_{\text {air }}\right)$ trends (Schneider and Hook 2010). Increased $T_{\text {surf }}$ affects the timing, duration and intensity of stratification and seasonal deep convective mixing (Livingstone 2003; Fang and Stefan 2009), as well as the timing and duration of ice cover (Weyhenmeyer et al. 2011). Lakes may shift from one seasonal mixing type to another if minimum temperatures exceed a certain threshold. Dimictic lakes may become monomictic (Livingstone 2008), while winter mixing may become incomplete or sporadic in monomictic lakes (Straile et al. 2003).

Changes in temperature and stratification further affect biological and geochemical processes. Oxygen concentrations may decrease in deep stratified lakes (Matzinger et al. 2007) and increase in ice-covered lakes (Fang and Stefan 2009). Nutrient availability for primary producers is expected to increase (Trolle et al. 2011), and harmful algal blooms are predicted to occur more frequently (Paerl and Paul 2012). Changes in the fish assemblage composition have already been observed (Jeppesen et al. 2012), while more complex interactions between physical and biological processes, such as a disruption of the linkage between different trophic levels (Winder and Schindler 2004) need further investigation. These and other effects of climate change on lakes have been discussed in several recent reviews (Adrian et al. 2009; George 2010; Shimoda et al. 2011; Winder and Sommer 2012). Furthermore, as reviewed by Adrian et al. (2009), lakes can be used as sentinels for current and past climate change, and near-surface temperature trends and ice phenology can be valuable indicators for changes in $T_{\text {air }}$. In summary, there is great interest in understanding past and future effects of climate change on physical, chemical and biological processes in lakes.

The Fourth Assessment Report (AR4) of the Intergovernmental Panel on Climate Change (IPCC 2007) provided an overview of the state of climate change predictions. Climate change was simulated for the same greenhouse gas emission scenarios by 23 different atmosphereocean general circulation models (AOGCMs). Predictions made for future $T_{\text {air }}$ trends are relatively robust, with uncertainties on the order of $\sim 50 \%$ (Knutti 2008), while those for other forcing variables such as wind speeds are less reliable, as the variation between models is often of a similar magnitude as the predicted changes.

The aim of the present study is to investigate the sensitivity of $T_{\text {surf }}$ to climate variables on a global scale. The sensitivity of $T_{\text {surf }}$ to $T_{\text {air }}$ has previously been investigated for individual lakes (e.g. Robertson and Ragotzkie 1990; Peeters et al. 2002; Verburg and Hecky 2009) or on a regional to continental scale (e.g. Stefan et al. 1998; Fang and Stefan 2009). All these studies concluded that $T_{\text {surf }}$ is expected to increase by 50 to $90 \%$ of $T_{\text {air }}$ Livingstone and Imboden (1989) showed that most of the interannual variation in $T_{\text {surf }}$ in Lake Aegeri was caused by variations in cloud cover and relative humidity, rather than $T_{\text {air }}$. Austin and Allen (2011) evaluated the sensitivity of $T_{\text {surf }}$ in Lake Superior to changes in $T_{\text {air }}$, wind speed, and the extent of ice cover in the previous winter. All three variables were shown to affect $T_{\text {surf }}$ to a similar extent.

In the present study, we aim to investigate the following questions:

1. How sensitively does $T_{\text {surf }}$ react to changes in meteorological forcing variables?

2. What is the relative importance of meteorological variables other than $T_{\text {air }}$ for future trends in $T_{\text {surf }}$ on a global scale?

3. What are the differences in the forcing mechanisms between different climate zones?

4. Do the answers to questions one to three depend on the choice of the AOGCM used to predict $T_{\text {surf }}$ ?

5. What are the resulting implications for climate change studies on lakes?

We use the lake surface equilibrium temperature $\left(T_{e q}\right)$, i.e., the temperature at which the net heat flux at the lake surface is zero for given meteorological conditions, as a proxy for $T_{\text {surf }}$. 
The implications of this choice are discussed in Section 4.1. It is important to note that the focus of the present study is not on trying to precisely predict changes in $T_{\text {surf }}$ globally and even less for specific lakes.

\section{Materials and methods}

\subsection{Climate scenarios}

Calculations are based on climate predicted for AR4 by the six AOGCMs BCCR-BCM2.0, CGCM3.1, CNRM-CM3, GISS-EH, INM-CM3.0, and MIROC3.2(hires), downloaded from the World Climate Research Programme's (WCRP) Coupled Model Intercomparison Project (CMIP3) database (Meehl et al. 2007). The models were chosen to represent a wide variety of the AOGCMs in AR4, by including models with different grid resolutions, and by selecting models which predict different spatial distributions of present-day surface temperatures (Fig. 2 in Knutti 2008). Details on model resolution, the number of grid cells considered and the downloaded variables are given in the supplementary material. Scenario 20C3M was used for the baseline climatology of 1961 to 1990 , and SRES A1B for the future climate of 2070 to 2099. SRES A1B has a medium impact, with a globally averaged increase in $T_{\text {air }}$ of $2.8^{\circ} \mathrm{C}(1.7$ to $4.4{ }^{\circ} \mathrm{C}$ ). Thirty-year arithmetic means were calculated from the monthly data for each grid cell and each month for both scenarios. The term anomaly, indicated with the symbol $\Delta$, is used in the following for the difference of the arithmetic means of any variable between the future climate and the baseline climatology.

\subsection{Calculation of lake surface equilibrium temperature}

$T_{e q}$ is defined as the temperature at which the net heat flux at the lake surface $\left(H_{t o t}\right)$, given by the sum of the individual heat fluxes $\left(H_{i}\right)$, is zero (Edinger et al. 1968):

$$
H_{\text {tot }}\left(T_{\text {eq }}\right)=H_{S}+H_{A}+H_{W}+H_{E}+H_{C}=0
$$

Heat fluxes from the atmosphere to the lake are defined to be positive. The lake gains heat from downward shortwave $\left(H_{S}\right)$ and longwave $\left(H_{A}\right)$ radiation, and emits heat by longwave radiation $\left(H_{W}\right)$. The latent heat flux $\left(H_{E}\right)$ due to evaporation or condensation, and the convective heat flux $\left(H_{C}\right)$ can be positive or negative. Numerous equations have been proposed to estimate the individual $H_{i}$ from the forcing variables $T_{\text {air }}$, vapour pressure $\left(e_{a}\right)$, cloudiness $(C)$, solar radiation at the lake surface $\left(H_{S O}\right)$ and wind speed $10 \mathrm{~m}$ above the lake surface $\left(u_{10}\right)$ (Henderson-Sellers 1986). The set of equations used in this study is given in the supplementary material, and is mainly based on Livingstone and Imboden (1989). The largest uncertainties due to the choice of equations result from the emissivity of the atmosphere $\left(E_{a}\right)$ for longwave radiation, and the equation for $H_{E}$. However, a sensitivity analysis showed that the influence of the choice of equations for these two factors on $\Delta T_{e q}$ was small (see supplementary material).

For each grid cell of the six AOGCMs, we calculated the fractions of wetland types defined in the Global Lakes and Wetlands Database (GLWD; Lehner and Döll 2004) and of the climate zones according to the revised Köppen-Geiger classification (Kottek et al. 2006). The climate zones were grouped in A (tropical), B (dry), C (temperate), D (continental), ET (tundra) and EP (ice caps). Each cell was assigned the climate zone of which it contained the largest fraction. The following rules were applied to decide whether a grid cell was included in the global 
analysis: grid cells with land fraction $(s f t l f)<10 \%$ were discarded except if they contained $>10 \%$ lakes in GLWD (sftlf is defined as the percentage of land surface in BCCR-BCM2.0, GISS-EH, and MIROC3.2(hires) and as either land or water in the other models; large lakes are not considered as land); cells with Köppen-Geiger classification EP were discarded; those with classification B were discarded, except if they contained more than $0.1 \%$ lakes, reservoirs or permanent wetlands in GLWD.

Finally, grid cells with $T_{e q} \leq 0{ }^{\circ} \mathrm{C}$ for either the 20C3M or the A1B scenario were excluded from the analysis. At $T_{e q} \leq 0{ }^{\circ} \mathrm{C}$ shallow lakes are expected to freeze and the used heat budget equations become invalid. In deep lakes, substantial amounts of heat can be stored in the deep water during the warm season, and $T_{e q}$ may need to remain below $0{ }^{\circ} \mathrm{C}$ for many weeks until enough of this heat has been released to the atmosphere such that an inverse stratification and subsequently an ice-cover can develop. For calculating global and zonal averages, grid cells were weighted by surface area. Data were averaged first spatially and then temporally.

\section{Results}

\subsection{Sensitivity of equilibrium temperature to forcing variables}

Before discussing the results of the calculations based on the AOGCMs, we evaluate the sensitivity of $T_{e q}$ to the forcing variables for a range of combinations of $T_{\text {air }}$ and relative humidity $\left(h_{r e l}\right)$ as well as for combinations of $T_{\text {air }}$ and $u_{10}$. The values of the other forcing variables are kept constant as given in the caption of Fig. 1.

The difference between $T_{e q}$ and $T_{\text {air }}$ (Fig. 1a) increases with decreasing $T_{\text {air }}$, and $u_{10}$, and with increasing $h_{r e l}$. $T_{e q}$ exceeds $T_{a i r}$ except for hot and dry conditions and for high wind speeds. Consequently, $T_{\text {surf }}$ is expected to be warmer than daily average $T_{\text {air }}$ once it has reached equilibrium.
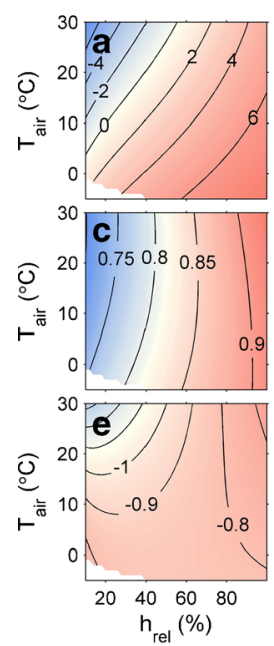
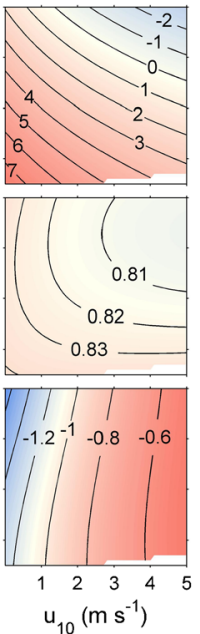
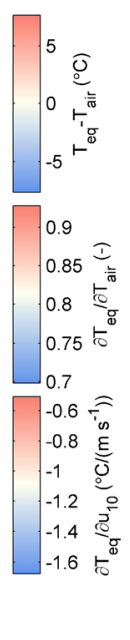
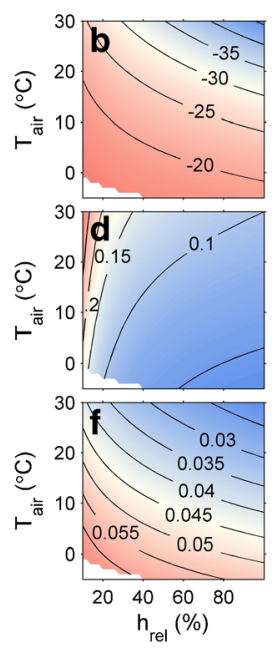
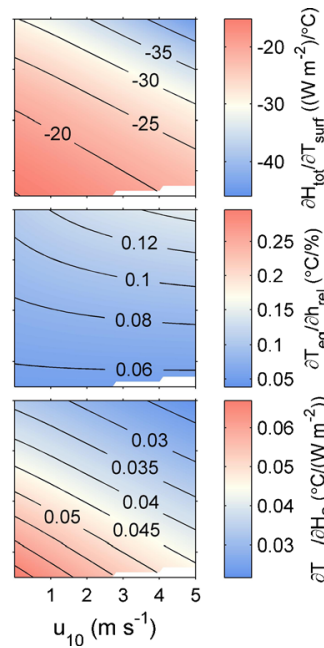

Fig. 1 a Difference between lake surface equilibrium temperature $T_{e q}$ and air temperature $T_{\text {air }} ; \mathbf{b}$ sensitivity of the total heat flux, $H_{\text {tot }}$, to changes in lake surface temperature, $T_{s u r} ; \mathbf{c}-\mathbf{f}$ sensitivity of $T_{e q}$ to changes in $\mathbf{c} T_{\text {air }}$, d relative humidity, $h_{r e l}$, $\mathbf{e}$ wind speed, $u_{10}$, and $\mathbf{f}$ solar radiation, $H_{S O}$; all as functions of $T_{\text {air }}$ and $h_{\text {rel }}$ (left panels) and $T_{\text {air }}$ and $u_{10}$ (right panels); The other forcing variables were kept constant at $C=0.5, H_{S}=200 \mathrm{~W} \mathrm{~m}^{-2}, p_{\text {air }}=$ $1,000 \mathrm{hPa}, u_{10}=2 \mathrm{~m} \mathrm{~s}^{-1}$ (left panels), and $h_{\text {rel }}=0.5$ (right panels). Note the different color scales 
But how long does it take for $T_{\text {surf }}$ to approach $T_{e q}$ ? A departure of $T_{\text {surf }}$ from $T_{\text {eq }}$ by $1{ }^{\circ} \mathrm{C}$ results in a $H_{t o t}$ of -20 to $-35 \mathrm{~W} \mathrm{~m}^{-2}$ (Fig. 1b). As an example, with $H_{t o t}=30 \mathrm{~W} \mathrm{~m}^{-2}$ the temperature of a $5 \mathrm{~m}$ thick surface mixed layer would increase by $\sim 0.12{ }^{\circ} \mathrm{C} \mathrm{d}^{-1}$ and thus exponentially approach $T_{e q}$ with a time scale of 8 days. If the mixed layer is thicker, the time scale increases correspondingly. The net heat flux resulting from a departure of $T_{\text {surf }}$ from $T_{e q}$ increases with $T_{\text {air }}$ (Fig. 1b), because both $H_{W}$ and $H_{E}$ increase more than linearly with $T_{\text {air }}$, and therefore also with $h_{r e l}$, because $T_{e q}$ increases significantly with $h_{r e l}$ (Fig. 1a). Consequently, $T_{\text {surf }}$ approaches $T_{e q}$ faster in warm and humid than in cold and dry climates.

Figure $1 \mathrm{c}$ to e show the sensitivities of $T_{e q}$ to changes in the individual forcing variables. $T_{e q}$ is typically expected to increase by 70 to $90 \%$ of $T_{\text {air }}$ (Fig. 1c). The sensitivity function $\partial T_{e q} /$ $\partial T_{\text {air }}$ is almost independent of $u_{10}$ and $T_{\text {air }}$ but increases under humid conditions, where a smaller fraction of the additional heat input is counterbalanced by increasing evaporation. The sensitivity to changes in $h_{r e l}$ is highest under warm and dry conditions (Fig. 1d). On average, $T_{e q}$ is predicted to increase by $\sim 0.1^{\circ} \mathrm{C}$ if $h_{\text {rel }}$ increases by $1 \%$. An increase of $u_{10}$ by $1 \mathrm{~m} \mathrm{~s}^{-1}$ leads to a decrease of $T_{e q}$ by $\sim{ }^{\circ} \mathrm{C}$ (Fig. 1e). This effect is stronger for calm, warm and dry conditions. The sensitivity of $T_{e q}$ to solar radiation (Fig. 1f) is directly related to the sensitivity of $H_{\text {tot }}$ to $T_{\text {surf }}$ (Fig. 1b), because any change in $H_{S}$ needs to be counterbalanced by a corresponding change in $T_{\text {surf }}$ to keep $H_{\text {tot }}=0$. The effect of changes in $H_{S}$ is therefore strongest in cold and dry climates. Typically, an increase in $H_{S}$ by $1 \mathrm{~W} \mathrm{~m}^{-2}$ leads to an increase in $T_{e q}$ by $0.03-0.06{ }^{\circ} \mathrm{C}$.

In summary, we conclude that $T_{e q}$ increases more slowly than $T_{a i r}$, that $T_{e q}$ is approached faster in warm climate zones, and that the sensitivity of $T_{e q}$ to changes in $h_{r e l}$ and $u_{10}$ increases while that to changes in $H_{S}$ decreases with $T_{\text {air }}$. The following rules of thumb can be used to derive a first estimate of the relative contributions of different forcing variables to changes in $T_{e q}$ : an increase in $T_{e q}$ by $1{ }^{\circ} \mathrm{C}$ is achieved by increasing $T_{\text {air }}$ by $1.2{ }^{\circ} \mathrm{C}$, decreasing $u_{10}$ by $1 \mathrm{~m} \mathrm{~s}^{-1}$, increasing $h_{\text {rel }}$ by $10 \%$, or increasing $H_{S}$ by $25 \mathrm{~W} \mathrm{~m}^{-2}$.

\subsection{Climate scenarios}

The anomalies of the meteorological variables predicted by the AOGCMs for the different climate zones are shown in Fig. 2. Five of the six models predict similar $\Delta T_{\text {air }}$, whereas MIROC3.2(hires) forecasts significantly higher warming, mainly because of a stronger shortwave cloud feedback (Yokohata et al. 2008). The average $\Delta T_{\text {air }}$ is similar for all climate zones, since the rule $T_{e q}>0{ }^{\circ} \mathrm{C}$ excludes winter months at high latitudes, for which generally a strong warming is predicted. Relative humidity and cloudiness are predicted to decrease in all climate zones. Average wind speed anomalies are almost consistently positive except for the continental climate zones. Solar radiation is expected to decrease in the tundra and continental zones with no consistent trends elsewhere.

\subsection{Lake surface equilibrium temperatures}

The anomalies in lake surface equilibrium temperature $\left(\Delta T_{e q}\right)$ and their global distribution vary significantly among the different models (Fig. 3). As expected from $\Delta T_{\text {air }}$, $\Delta T_{e q}$ calculated based on the model MIROC3.2(hires) was highest, especially in the continental climate zone (Table 1) and between 40 and $70^{\circ} \mathrm{N}$ (see supplementary material). High $\Delta T_{e q}$ were consistently predicted in the region of the Laurentian Great Lakes and in the Amazon Basin. Similar to $\Delta T_{\text {air }}, \Delta T_{e q}$ is comparably low at high latitudes for several models because only months with $T_{e q}>0{ }^{\circ} \mathrm{C}$ were considered. The average predicted $\Delta T_{e q}$ is $\sim 70 \%$ of $\Delta T_{\text {air }}$ in dry and tundra climates, $\sim 80 \%$ in tropical and temperate climates, and $\sim 85 \%$ in continental climates (Table 1). 

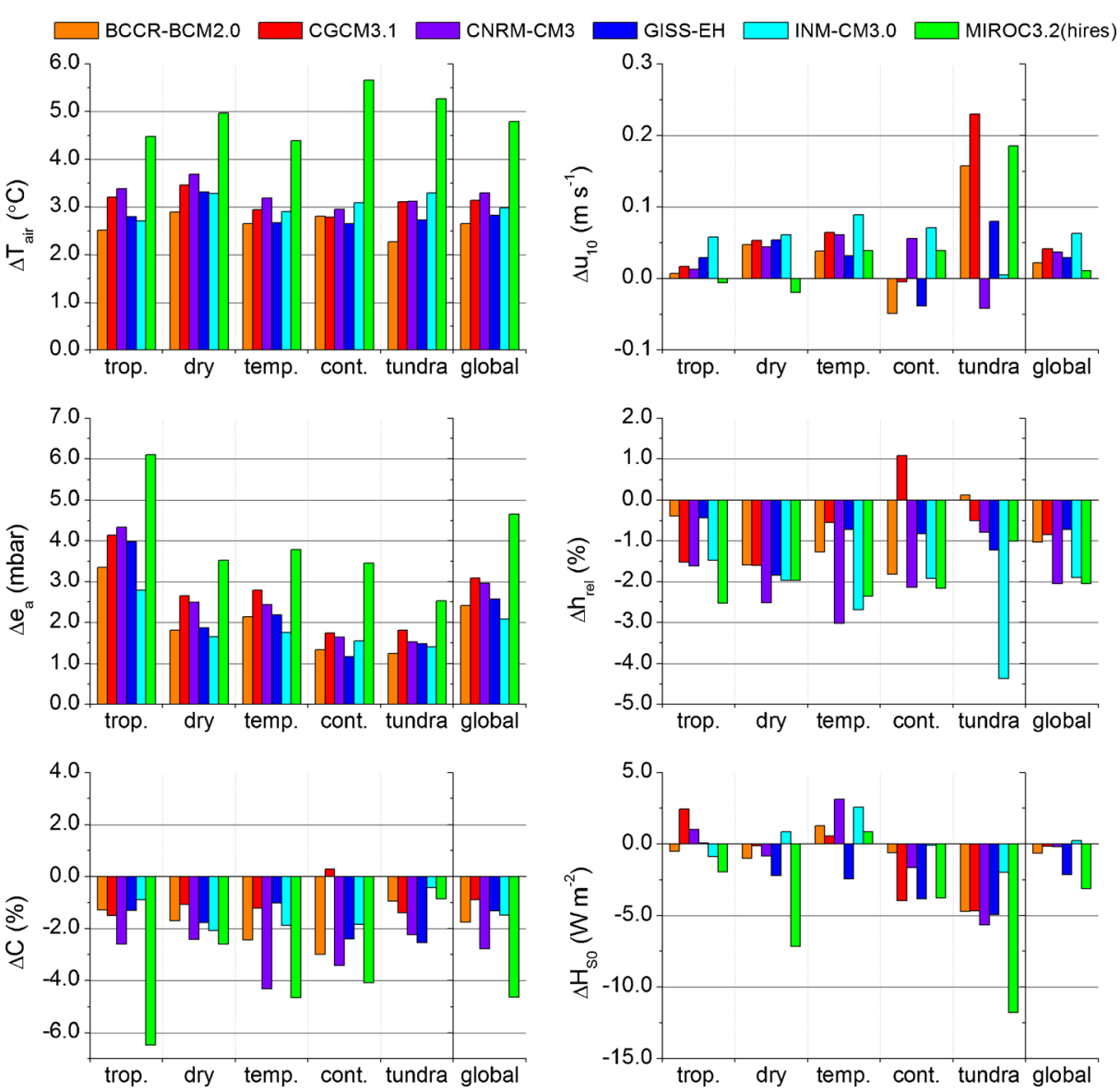

Fig. 2 Mean anomalies of the forcing variables in six AOGCMs in the SRES A1B scenario in 2070 to 2099 with respect to 1961 to 1990 , for different climate zones and averaged globally. Only land grid cells with $T_{e q}>0{ }^{\circ} \mathrm{C}$ were considered for the averaging

\subsection{Heat fluxes}

The net heat flux $H_{t o t}$ at $T_{e q}$ and therefore also its anomaly $\Delta H_{t o t}$ are per definition both equal to zero. However, the components $H_{i}$ of $H_{\text {tot }}$ do change (Fig. 4). $H_{A}$ on average increases by $\sim 20 \mathrm{~W} \mathrm{~m}^{-2}$ ( $\sim 30 \mathrm{~W} \mathrm{~m}^{-2}$ for MIROC3.2(hires)), which is partially offset by a corresponding $\Delta H_{W}$ of $\sim-15 \mathrm{~W} \mathrm{~m}^{-2}$ ( - $20 \mathrm{~W} \mathrm{~m}^{-2}$ for MIROC3.2(hires)). Both $H_{A}$ and $H_{W}$ change more at low than at high latitudes. $\Delta H_{E}$ is negative, i.e., evaporation is predicted to increase, for all models in all climate zones. Conversely, positive $\Delta H_{C}$ of a few $\mathrm{W} \mathrm{m}^{-2}$ are predicted because $T_{\text {surf }}$ increases less than $T_{\text {air }}$. For most lakes, $H_{C}$ is negative for the present climate. On average, the absolute value of $H_{C}$ decreases by $\sim 20 \%$. The average $\Delta H_{S}$ is small, except for a decrease by $\sim 5 \mathrm{~W} \mathrm{~m}^{-2}$ in the tundra zone. These changes result in a shift in the importance of the contributions of the individual heat fluxes to the heat budget: longwave radiation gains importance as a heat source compared to shortwave radiation, and evaporation gains importance as a heat loss compared to both longwave radiation and the convective heat flux. 

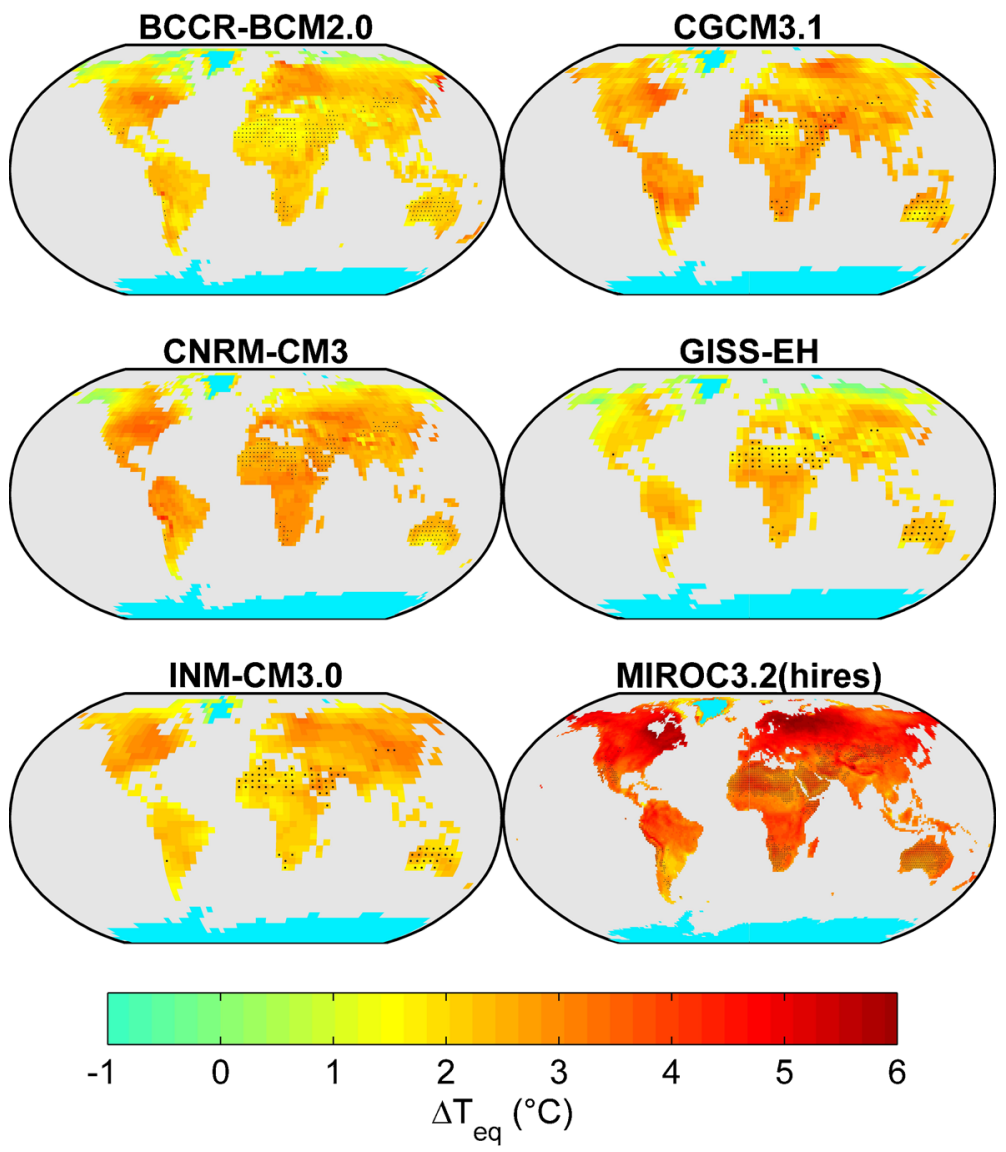

Fig. 3 Annual mean predicted $\Delta T_{e q}$ in 2070 to 2099 with respect to 1961 to 1990 based on six AOGCMs. Only grid cells and months with $T_{e q}>0{ }^{\circ} \mathrm{C}$ were considered. Cells containing less than $0.1 \%$ wetlands in the GLWD with Köppen-Geiger classification polar (marked in blue) or dry (marked with black dots) were excluded from the calculations of global and zonal averages

\subsection{Contributions of the different driving variables}

In order to determine the contributions of the forcing variables to $\Delta T_{e q}$, we recalculated $\Delta T_{e q}$ using the future climate for each variable while keeping all other variables at the baseline climatology. For $\Delta T_{\text {air }}$, we calculated two scenarios, keeping either $e_{a}$ or $h_{r e l}$ at the baseline. The results are displayed in Fig. 5. For all models and climate zones $\Delta T_{\text {air }}$ is the most important driving variable, and the only one that on average increases $T_{e q}$. The warming by $\Delta T_{\text {air }}$ would be reduced by 40 to $50 \%$ due to increased evaporation and a lower increase of $H_{A}$ if $e_{a}$ remained constant. However, the AOGCMs consistently predict that $e_{a}$ follows $T_{a i r}$ with only a slight average reduction in $h_{\text {rel }}$.

In total, the anomalies of the variables besides $\Delta T_{\text {air }}$ reduce the warming caused by $\Delta T_{\text {air }}$ on average by only $\sim 9 \%$, half of which is due to the decrease in $h_{r e l}$. Nevertheless, these variables can be important at specific locations. This is highlighted by the root mean square (rms) of the contributions of the different variables (Fig. 5) which is a measure of the variability they 
Table 1 Annual mean anomaly of the lake surface equilibrium temperature, $\Delta T_{e q}\left({ }^{\circ} \mathrm{C}\right)$, in 2070 to 2099 with respect to 1961 to 1990 based on six AOGCMs for five different climate zones and globally. In parentheses: $\Delta T_{e q}$ as a percentage of $\Delta T_{\text {air }}$, and average number of months per year with $T_{e q}>0{ }^{\circ} \mathrm{C}$

\begin{tabular}{|c|c|c|c|c|c|c|}
\hline & \multicolumn{6}{|c|}{$\begin{array}{l}\Delta \mathrm{T}_{\mathrm{eq}}\left({ }^{\circ} \mathrm{C}\right) \\
\left(\% \text { of } \Delta \mathrm{T}_{\text {air }} \text {, average number of months }\right)\end{array}$} \\
\hline & Tropical & Dry & Temperate & Continental & Tundra & Global \\
\hline BCCR-BCM2.0 & $\begin{array}{l}2.11 \\
(84 \%, 12)\end{array}$ & $\begin{array}{l}2.07 \\
(71 \%, 10.9)\end{array}$ & $\begin{array}{l}2.23 \\
(84 \%, 11.2)\end{array}$ & $\begin{array}{l}2.41 \\
(86 \%, 6.2)\end{array}$ & $\begin{array}{l}1.79 \\
(79 \%, 5.1)\end{array}$ & $\begin{array}{l}2.14 \\
(81 \%, 9.5)\end{array}$ \\
\hline CGCM3.1 & $\begin{array}{l}2.67 \\
(83 \%, 12)\end{array}$ & $\begin{array}{l}2.57 \\
(74 \%, 10.8)\end{array}$ & $\begin{array}{l}2.53 \\
(86 \%, 10.9)\end{array}$ & $\begin{array}{l}2.55 \\
(92 \%, 6.0)\end{array}$ & $\begin{array}{l}2.28 \\
(73 \%, 5.0)\end{array}$ & $\begin{array}{l}2.57 \\
(82 \%, 9.4)\end{array}$ \\
\hline CNRM-CM3 & $\begin{array}{l}2.77 \\
(82 \%, 12)\end{array}$ & $\begin{array}{l}2.71 \\
(73 \%, 11.0)\end{array}$ & $\begin{array}{l}2.57 \\
(81 \%, 11.4)\end{array}$ & $\begin{array}{l}2.46 \\
(83 \%, 6.6)\end{array}$ & $\begin{array}{l}2.42 \\
(78 \%, 5.8)\end{array}$ & $\begin{array}{l}2.62 \\
(80 \%, 9.6)\end{array}$ \\
\hline GISS-EH & $\begin{array}{l}2.30 \\
(82 \%, 12)\end{array}$ & $\begin{array}{l}2.17 \\
(65 \%, 11.1)\end{array}$ & $\begin{array}{l}2.05 \\
(77 \%, 11.3)\end{array}$ & $\begin{array}{l}2.01 \\
(76 \%, 6.5)\end{array}$ & $\begin{array}{l}1.75 \\
(64 \%, 5.6)\end{array}$ & $\begin{array}{l}2.12 \\
(75 \%, 9.7)\end{array}$ \\
\hline INM-CM3.0 & $\begin{array}{l}2.02 \\
(75 \%, 12)\end{array}$ & $\begin{array}{l}2.33 \\
(71 \%, 11.2)\end{array}$ & $\begin{array}{l}2.25 \\
(78 \%, 11.6)\end{array}$ & $\begin{array}{l}2.69 \\
(87 \%, 6.8)\end{array}$ & $\begin{array}{l}2.37 \\
(72 \%, 5.4)\end{array}$ & $\begin{array}{l}2.27 \\
(76 \%, 9.8)\end{array}$ \\
\hline MIROC3.2(hires) & $\begin{array}{l}3.46 \\
(77 \%, 12)\end{array}$ & $\begin{array}{l}3.53 \\
(71 \%, 11.0)\end{array}$ & $\begin{array}{l}3.57 \\
(81 \%, 11.7)\end{array}$ & $\begin{array}{l}4.82 \\
(85 \%, 6.9)\end{array}$ & $\begin{array}{l}3.66 \\
(70 \%, 5.7)\end{array}$ & $\begin{array}{l}3.76 \\
(78 \%, 9.8)\end{array}$ \\
\hline Multi-model mean & $\begin{array}{l}2.56 \\
(80 \%, 12)\end{array}$ & $\begin{array}{l}2.56 \\
(71 \%, 11.0)\end{array}$ & $\begin{array}{l}2.53 \\
(81 \%, 11.4)\end{array}$ & $\begin{array}{l}2.82 \\
(85 \%, 6.5)\end{array}$ & $\begin{array}{l}2.38 \\
(72 \%, 5.4)\end{array}$ & $\begin{array}{l}2.58 \\
(79 \%, 9.6)\end{array}$ \\
\hline
\end{tabular}

induce to $\Delta T_{e q}$. On average, the variability caused by variables other than $\Delta T_{\text {air }}$ is $\sim 40 \%$ of that caused by $\Delta T_{\text {air }}$. The variability caused by $\Delta H_{S}$ increases with latitude, while that induced by $\Delta h_{r e l}$ is highest in warm dry regions.

The correlations between anomalies in the driving variables and $\Delta T_{e q}$ are, as expected, strongest for $\Delta T_{\text {air }}$, positive for $\Delta T_{\text {air }}$ and $\Delta H_{S 0}$, and negative for $\Delta h_{r e l}, \Delta u_{10}$ and $\Delta C$. Interestingly, the correlation between $\Delta T_{\text {air }}$ and $\Delta T_{e q}$ significantly increases with latitude, reaching values of $r=0.8$ for continental and tundra climates, but only 0.5 for tropical climates, even though most of $\Delta T_{e q}$ is caused by $\Delta T_{\text {air }}$ in all climate zones. Conversely, the correlation of $\Delta T_{e q}$ with $\Delta u_{10}$ becomes weaker from -0.5 for tropical climates to -0.2 for tundra and continental climates. The correlations with $\Delta u_{10}$ are surprisingly strong considering that $\Delta u_{10}$ contributes little to the average and rms of $\Delta T_{e q}$. The reason for these trends in correlations is the growing importance of $H_{E}$ and its anomaly compared to $H_{A}$ and $H_{W}$ towards lower latitudes (Fig. 4). $\Delta H_{S 0}$ and $\Delta h_{\text {rel }}$ are generally strongly negatively correlated ( $\left.\mathrm{r} \sim-0.6\right)$, because of the positive correlation between $\Delta H_{S 0}$ and $\Delta C$. Since $H_{\text {tot }}$ increases both with $H_{S O}$ and $h_{r e l}$, their effects on $\Delta T_{e q}$ partially cancel each other.

\section{Discussion}

\subsection{Equilibrium temperatures versus real surface temperatures}

For shallow lakes, i.e., for the majority of lakes worldwide, $T_{e q}$ is a good proxy for $T_{\text {surf }}$ on the seasonal time scale (Wilhelm et al. 2006). It has also been shown to be linearly related to observed stream temperatures, although these are often modified by groundwater, shading, or meltwater (Bogan et al. 2003). Furthermore, $\Delta T_{e q}$ is an even better proxy for $\Delta T_{\text {surf }}$, as systemspecific differences between $T_{e q}$ and $T_{\text {surf }}$ are largely cancelled by taking the difference between the future and the baseline scenario. 


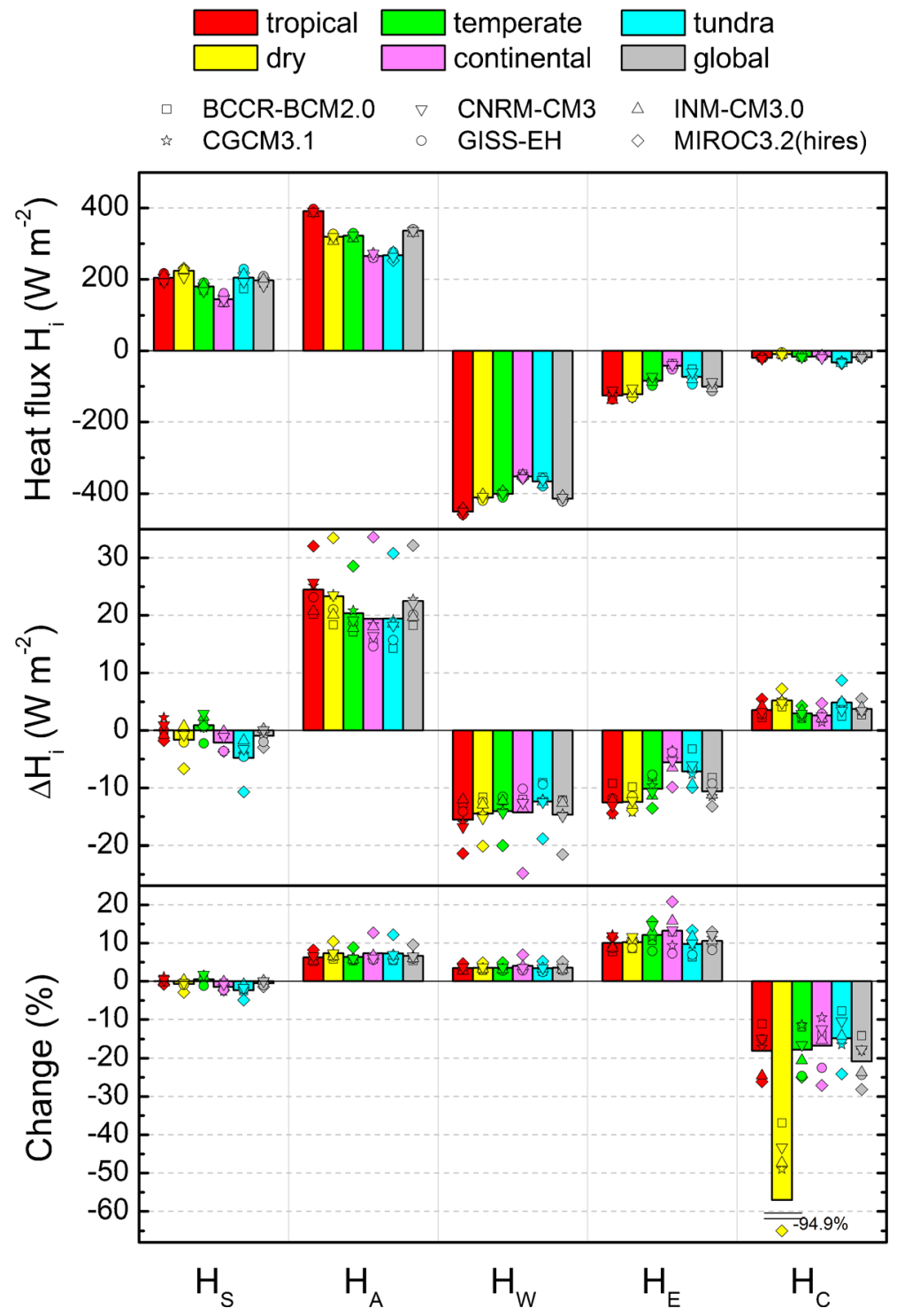

Fig. 4 Average lake surface heat fluxes $H_{i}$ (individual components $i$ of $H_{t o t}$ ) and their anomalies (absolute and relative) in 2070 to 2099 with respect to 1961 to 1990 , calculated from the output of six AOGCMs for five different climate zones and globally. The number of grid cells and average number of months considered for each model and climate zone are specified in Table S1 (see supplementary material) and Table 1, respectively. Bars indicate multi-model means, symbols values for individual models

In deep lakes, however, $T_{\text {surf }}$ is strongly modified by mixing processes. When they are stratified and surface mixed layers are thin, e.g. during spring and summer in temperate lakes, $T_{e q}$ is a good measure of $T_{\text {surf }}$ (see supplementary material). But during periods of deep mixing larger water volumes are involved in the surface heat balance and $T_{\text {surf }}$ responds slowly to changes in $T_{e q}$ (Livingstone and Lotter 1998). For most temperate and boreal deep lakes, 


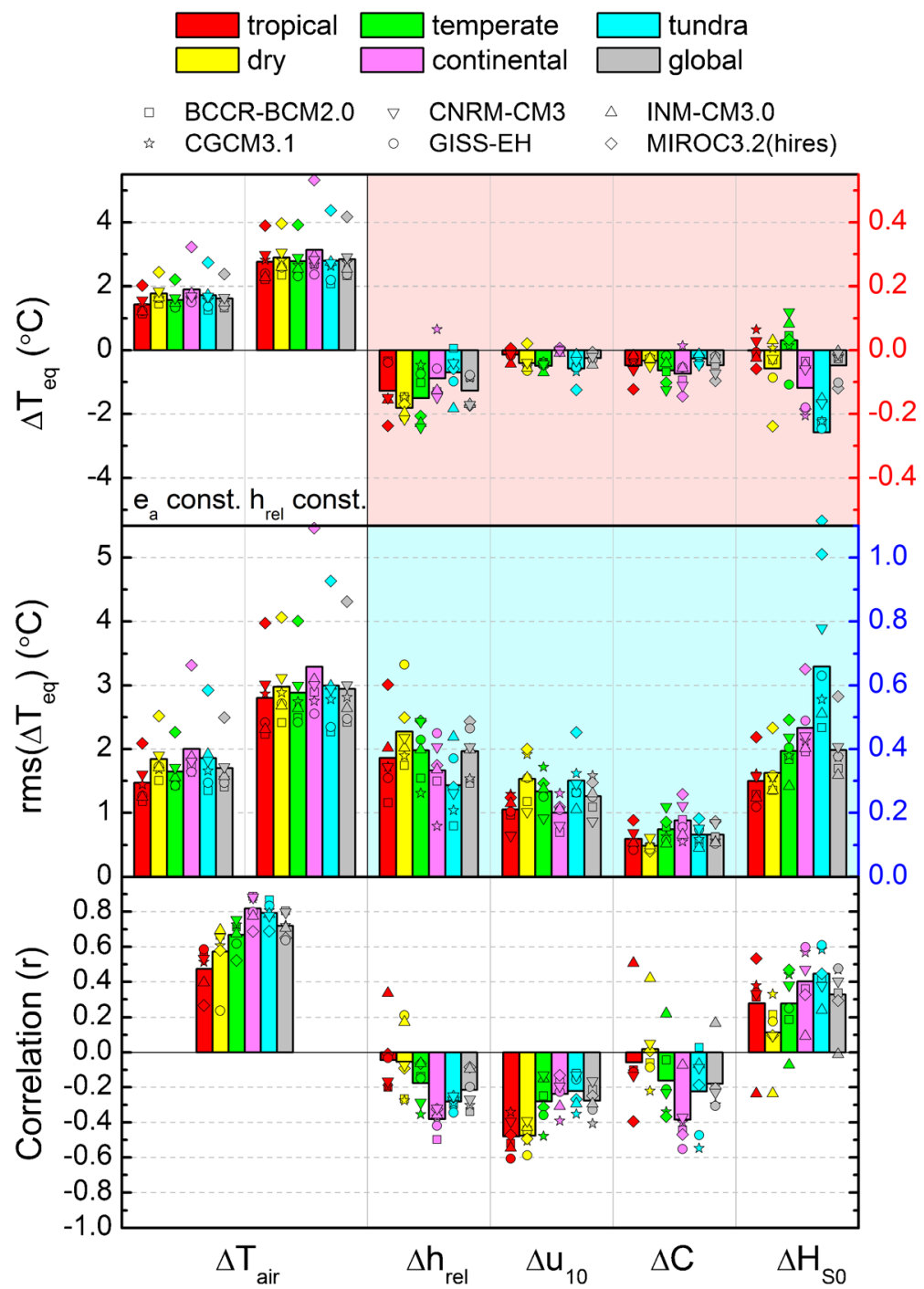

Fig. 5 Effects of the anomalies (2070 to 2099 with respect to 1961 to 1990) of single meteorological forcing variables on $\Delta T_{e q}$, calculated from the output of six AOGCMs for five different climate zones and globally. From top to bottom: average effect on $\Delta T_{\text {eq }}$; root-mean squared (rms) effect on $\Delta T_{\text {eq }}$, and correlation coefficients ( $\mathrm{r}$ ) between $\Delta T_{e q}$ and the anomalies of the forcing variables. The number of grid cells and average number of months considered for each model and climate zone are specified in Table S1 (see supplementary material) and Table 1, respectively. Bars indicate multi-model means, symbols values for individual models. Note that the contributions of variables other than $T_{\text {air }}$ were stretched by factors of 10 (red panel; right axis) and 5 (blue panel; right axis) compared to those of $T_{\text {air }}$

however, periods of deep mixing occur mainly during months when $T_{e q} \leq 0{ }^{\circ} \mathrm{C}$ and are thus not included in our evaluation.

As wind strongly affects mixing in lakes, the relative effect of wind speed on $T_{\text {surf }}$ should be greater than that on $T_{e q}$. The effects of wind speed could be additionally underestimated for two reasons: Local winds can exceed the average large scale winds predicted by AOGCMs; and the predicted changes in the difference between air and lake temperatures can modify winds 
created by large lakes. For example, Desai et al. (2009) showed that winds created by Lake Superior have intensified due to the decreasing difference between $T_{\text {air }}$ and $T_{\text {surf }}$, and that the effects of wind speed and $T_{\text {air }}$ on trends in $T_{\text {surf }}$ were of similar importance.

Water transparency further modifies $T_{\text {surf }}$. In clear, stratified lakes, a significant fraction of $H_{S}$ penetrates the surface mixed layer and does not contribute directly to its heat budget. Consequently, $T_{\text {surf }}$ can be significantly below $T_{e q}$ (Rinke et al. 2010). Furthermore, an increase in $H_{A}$, which is absorbed at the lake surface, has a different effect on the thermal stratification of a clear lake than an increase in $H_{S}$, although they both equally affect $T_{e q}$. The predicted $\Delta T_{e q}$ is mainly due to changes in heat fluxes that are absorbed or emitted directly at the lake surface (Fig. 4). In combination these effects contribute to the trend toward shallower thermocline depths and stronger stratification that has been observed in clear, stratified lakes (Coats et al. 2006; Livingstone 2003). Conversely, in turbid lakes $T_{\text {surf }}$ decreases with increasing turbidity, as sunlight can only warm up a fraction of the layer that is mixed every night (Houser 2006). Finally, $T_{\text {surf }}$ can be modified by inflows, especially in lakes with short residence times, or by extensive lake level variations (Rimmer et al. 2011).

These individual response mechanisms highlight that the results of our study should not be used to predict changes in $T_{\text {surf }}$ for a specific lake. For this purpose, it is more advisable to use a specifically calibrated lake model in combination with climate forcing derived from a regional climate model, as it has been done for example by Komatsu et al. (2007) for Lake Biwa. Nevertheless, lake surface temperatures, especially during summer, have been shown to be regionally highly coherent, and largely driven by the regional climate forcing (Livingstone et al. 2010).

\subsection{Sensitivity of lake surface temperature to air temperature}

The predicted $\Delta T_{e q}$ of 70 to $85 \%$ of $\Delta T_{\text {air }}$ agrees well with previous studies. Hondzo and Stefan (1993) simulated temperature and stratification in Minnesota lakes of different size and depth for a climate scenario with doubled atmospheric $\mathrm{CO}_{2}$ concentrations. Average epilimnion temperatures increased by $\sim 3.0^{\circ} \mathrm{C}$ or $\sim 70 \%$ of the increase in $T_{\text {air }}$ of $4.4^{\circ} \mathrm{C}$. Fang and Stefan (2009) made analogous simulations for the contiguous United States. Mean annual $T_{\text {air }}$ increased by $6.7{ }^{\circ} \mathrm{C}$, mean annual $T_{\text {surf }}$ by $5.2{ }^{\circ} \mathrm{C}$, or $78 \%$ of the increase in $T_{\text {air }}$. River temperatures have been predicted to increase by approximately $65 \%$ of the increase in $T_{\text {air }}$, provided that discharge remains constant (van Vliet et al. 2011).

\subsection{Implications for studies of climate change effects on lakes}

In the following we discuss the implications of our results for different approaches to estimate climate change effects on lakes. Following the space-for-time approach, climate change effects are inferred from existing climate gradients, either altitudinal (Karlsson et al. 2005) or latitudinal (Weyhenmeyer 2008). However, lakes over a latitudinal gradient are not only subject to different $T_{\text {air }}$, but also to different day lengths that are not affected by climate change, as well as to different contributions of individual $H_{i}$ (Fig. 4). Livingstone et al. (2005) showed a clear relationship between $T_{\text {surf }}$ and smoothed $T_{\text {air }}$ in summer for 29 Swiss alpine lakes spanning an altitude range of 2,000 m. In this study the lapse rate of $T_{\text {surf }}$ exceeded that of $T_{\text {air }}$, in contrast to the expectations from our calculations. This suggests that the decrease in $T_{\text {surf }}$ with altitude results not only from decreasing $T_{\text {air }}$, but also from gradients in other variables such as cloud cover or snowmelt. Lakes at different altitudes or latitudes are therefore not necessarily a good surrogate for predicting climate change effects. 
Modeling studies are another common approach to predicting climate change effects on physical and biogeochemical processes in lakes. Often, the output from a global or a regionally downscaled climate model is used to drive such models (Fang and Stefan 2009). This has the advantage of covering the influences of all major driving variables. However, the different processes can be difficult to disentangle, and uncertainties in the prediction of some climate variables may blur the effects of variables such as $T_{\text {air }}$ that can be predicted with higher confidence. For example, large and highly uncertain wind speed anomalies in autumn significantly affected predictions by Stefan et al. (1996). These issues can be avoided by modifying individual variables, such as $T_{\text {air }}$ or $u_{10}$ (Trolle et al. 2011), but then negative or positive feedbacks caused by correlations between climate variables may be overlooked. Furthermore, large lakes influence the local climate, and coupled lake-climate models may be required to understand how global change modifies such climate-lake systems (Martynov et al. 2010).

Our results confirm that, on average for a large number of sites, changing only $T_{\text {air }}$ should result in good approximations for predicting climate change effects on $T_{\text {surf }}$. However, there are three caveats: first, this is not necessarily true for specific locations, where changes in other driving variables might be as important as changes in $T_{\text {air }}$. Second, it is conceivable that climate models fail to correctly predict changes in variables such as $u_{10}, e_{a}, C$, or $H_{S 0}$. Third, if a model is driven by specific humidity, it is important to increase specific humidity to ensure that $h_{r e l}$ remains constant, even though this might lead to $\Delta T_{e q}$ being overestimated in cases where there is not sufficient water available for humidity to follow $T_{\text {air }}$ Keeping specific humidity constant on average results in an underestimation of $\Delta T_{e q}$ by $\sim 40 \%$.

The comparably weak correlation between $\Delta T_{e q}$ and $\Delta T_{\text {air }}$ in tropical and dry climate zones might be regarded as a caveat for the use of biotic and abiotic proxies in sediment records for reconstructing past $T_{\text {air }}$. Such records are especially valuable in the tropics, where the potential of other climate archives such as ice cores and tree rings is limited (Verschuren 2003). However, reconstructing past climate from lake sediments requires conceptual models for the dependence of sediment proxies on climatic forcing. Often complex interactions are involved, and for some proxies, e.g. branched glycerol dialkyl glycerol tetraethers (Loomis et al. 2012), or chironomid assemblages (Eggermont et al. 2010), it is not yet clear to what extent they record air or water temperatures. If they record water temperatures, our results indicate that these are not necessarily well correlated to $T_{\text {air }}$, especially in tropical regions. This highlights the importance of understanding all processes connecting the driving variable (usually $T_{\text {air }}$ ) with the formation of a proxy variable in lacustrine sediments.

Finally, even though predictions derived from different AOGCMs generally agree, significant deviations for specific models and parameters exist. As discussed above, MIROC3.2(hires) results in much higher $\Delta T_{e q}$, and the spatial distribution of $\Delta T_{e q}$ differs between models. All models predict negative correlations between $\Delta \mathrm{C}$ and $\Delta T_{e q}$ except INM-CM3.0. The reason is that $\Delta C$ is strongly related to $\Delta e_{a}(r=0.50)$ in INMCM3.0, whereas this correlation is weak or even negative in the other models ( $\mathrm{r}$ between -0.27 and 0.18 ) where $\Delta C$ is much more related to $\Delta h_{r e l}$. As a consequence, also the correlation between $\Delta H_{S O}$ and $\Delta T_{e q}$ is much weaker in INM-CM3.0 than in the other models. Furthermore, the models significantly differ in the predicted effects of forcing variables other than $T_{\text {air }}$. For example, the rms of the contribution of $\Delta u_{10}$ to $\Delta T_{e q}$ is almost twice as high for CGCM3.1 as for CNRM-CM3, and that of $\Delta H_{S O}$ is $\sim 50 \%$ higher in MIROC3.2(hires) than in the other models. It is therefore advisable to use the output of several climate models for predicting climate change effects on lake surface temperatures and for evaluating the importance of different drivers. 


\section{Conclusions}

On a global scale, the warming of lakes during the $21^{\text {st }}$ century is expected to be mainly driven by increasing $T_{\text {air }}$. In agreement with previous studies, $T_{e q}$ are predicted to increase by $\sim 70$ to $85 \%$ of the increase in $T_{\text {air }}$. The warming caused by $T_{\text {air }}$ is on average reduced by $\sim 10 \%$ by changes in other meteorological variables. However, on a local scale and for specific lakes, the effects of other variables can be of similar importance as those of $T_{\text {air }}$. Especially in tropical regions, the correlations between $\Delta T_{e q}$ and $\Delta T_{\text {air }}$ are relatively low, and lake temperature proxies are not necessarily good proxies for past changes in $T_{\text {air }}$. The relative contributions of the individual heat fluxes to the heat budget of lakes are expected to change, as incoming longwave radiation and evaporation gain importance compared to the other heat fluxes. The predicted changes are generally similar for all AOGCMs used in this study, but some relevant differences exist. It is therefore advisable to use the output of a few different AOGCMs for robust predictions of climate change effects on lakes.

Acknowledgments We acknowledge the modeling groups, the Program for Climate Model Diagnosis and Intercomparison (PCMDI) and the WCRP's Working Group on Coupled Modelling (WGCM) for their roles in making available the WCRP's CMIP3 multi-model dataset. Support of this dataset is provided by the Office of Science, U.S. Department of Energy. We thank John C. Little for contributing to the literature review, David M. Livingstone and Andy F. Lotter for reviewing a previous version of this manuscript, and B. Henderson-Sellers and three anonymous reviewers for their constructive comments.

\section{References}

Adrian R, O’Reilly CM, Zagarese H et al (2009) Lakes as sentinels of climate change. Limnol Oceanogr 54: 2283-2297

Austin JA, Allen J (2011) Sensitivity of summer Lake Superior thermal structure to meteorological forcing. Limnol Oceanogr 56:1141-1154

Bogan T, Mohseni O, Stefan HG (2003) Stream temperature-equilibrium temperature relationship. Water Resour Res 39:1245

Coats R, Perez-Losada J, Schladow G, Richards R, Goldman C (2006) The warming of Lake Tahoe. Clim Chang 76:121-148

Desai AR, Austin JA, Bennington V, McKinley GA (2009) Stronger winds over a large lake in response to weakening air-to-lake temperature gradient. Nat Geosci 2:855-858

Edinger JE, Duttweiler DW, Geyer JC (1968) The response of water temperatures to meteorological conditions. Water Resour Res 4:1137-1143

Eggermont H, Heiri O, Russell J, Vuille M, Audenaert L, Verschuren D (2010) Paleotemperature reconstruction in tropical Africa using fossil Chironomidae (Insecta: Diptera). J Paleolimnol 43:413-435

Fang X, Stefan H (2009) Simulations of climate effects on water temperature, dissolved oxygen, and ice and snow covers in lakes of the contiguous United States under past and future climate scenarios. Limnol Oceanogr 54:2359-2370

George G (ed) (2010) The impact of climate change on European lakes. Aquat Ecol Ser 4, Springer, Dordrecht, 507 pp

Henderson-Sellers B (1986) Calculating the surface energy balance for lake and reservoir modeling: a review. Rev Geophys 24:625-649

Hondzo M, Stefan H (1993) Regional water temperature characteristics of lakes subjected to climate change. Clim Chang 24:187-211

Houser JN (2006) Water color affects the stratification, surface temperature, heat content, and mean epilimnetic irradiance of small lakes. Can J Fish Aquat Sci 63:2447-2455

IPCC (2007) Climate Change 2007: The Physical Science Basis. Contribution of Working Group I to the Fourth Assessment Report of the IPCC. Cambridge University Press, Cambridge

Jeppesen E, Mehner T, Winfield IJ et al (2012) Impacts of climate warming on the long-term dynamics of key fish species in 24 European lakes. Hydrobiologia 694:1-39 
Karlsson J, Jonsson A, Jansson M (2005) Productivity of high-altitude lakes: climate effect inferred from altitude gradient. Glob Chang Biol 11:710-715

Knutti R (2008) Should we believe model predictions of future climate change? Phil Trans R Soc A 366:46474664

Komatsu E, Fukushima T, Harasawa H (2007) A modeling approach to forecast the effect of long-term climate change on lake water quality. Ecol Model 209:351-366

Kottek M, Grieser J, Beck C, Rudolf B, Rubel F (2006) World Map of the Köppen-Geiger climate classification updated. Meteorol Z 15:259-263

Lehner B, Döll P (2004) Development and validation of a global database of lakes, reservoirs and wetlands. J Hydrol 296:1-22

Livingstone DM (2003) Impact of secular climate change on the thermal structure of a large temperate central European lake. Clim Chang 57:205-225

Livingstone DM (2008) A change of climate provokes a change of paradigm: taking leave of two tacit assumptions about physical lake forcing. Int Rev Hydrobiol 93:404-414

Livingstone DM, Imboden DM (1989) Annual heat balance and equilibrium temperature of Lake Aegeri, Switzerland. Aquat Sci 51:351-369

Livingstone DM, Lotter AF (1998) The relationship between air and water temperatures in lakes of the Swiss Plateau: a case study with palaeolimnological implications. J Paleolimnol 19:181-198

Livingstone DM, Lotter AF, Kettle H (2005) Altitude-dependent differences in the primary physical response of mountain lakes to climatic forcing. Limnol Oceanogr 50:1313-1325

Livingstone DM, Adrian R, Arvola L et al (2010) Regional and supra-regional coherence in limnological variables. In: George G (ed) The impact of climate change on European Lakes. Springer, Dordrecht, pp 311-337

Loomis SE, Russell JM, Ladd B, Street-Perrot FA, Sinninghe Damsté JS (2012) Calibration and application of the branched GDGT temperature proxy on East African lake sediments. Earth Planet Sci Lett 357-358:277288

Martynov A, Sushama L, Laprise R (2010) Simulation of temperate freezing lakes by one-dimensional lake models: performance assessment for interactive coupling with regional climate models. Boreal Environ Res $15: 143-164$

Matzinger A, Schmid M, Veljanoska-Sarafiloska E, Patceva S, Guseska D, Wagner B, Müller B, Sturm M, Wüest A (2007) Eutrophication of ancient Lake Ohrid: global warming amplifies detrimental effects of increased nutrient inputs. Limnol Oceanogr 52:338-353

Meehl GA, Covey C, Delworth T, Latif M, McAvaney B, Mitchell JFB, Stouffer RJ, Taylor KE (2007) The WCRP CMIP3 multimodel dataset: a new era in climate change research. Bull Am Meteorol Soc 88:13831394

Paerl HW, Paul VJ (2012) Climate change: links to global expansion of harmful cyanobacteria. Water Res 46: 1349-1363

Peeters F, Livingstone DM, Goudsmit G-H, Kipfer R, Forster R (2002) Modeling 50 years of historical temperature profiles in a large central European lake. Limnol Oceanogr 47:186-197

Rimmer A, Gal G, Opher T, Lechinsky Y, Yacobi YZ (2011) Mechanisms of long-term variations in the thermal structure of a warm lake. Limnol Oceanogr 56:974-988

Rinke K, Yeates P, Rothhaupt K-O (2010) A simulation study of the feedback of phytoplankton on thermal structure via light extinction. Freshw Biol 55:1674-1693

Robertson DM, Ragotzkie RA (1990) Changes in the thermal structure of moderate to large sized lakes in response to changes in air temperatures. Aquat Sci 52:360-380

Schneider P, Hook SJ (2010) Space observations of inland water bodies show rapid surface warming since 1985. Geophys Res Lett 37, L22405

Shimoda Y, Azim ME, Perhar G, Ramin M, Kenney MA, Sadraddini S, Gudimov A, Arhonditsis GB (2011) Our current understanding of lake ecosystem response to climate change: what have we really learned from the north temperate deep lakes? J Great Lakes Res 37:173-193

Stefan HG, Hondzo M, Fang X, Eaton JG, McCormick JH (1996) Simulated long-term temperature and dissolved oxygen characteristics of lakes in the north-central United States and associated fish habitat limits. Limnol Oceanogr 41:1124-1135

Stefan HG, Fang X, Hondzo M (1998) Simulated climate change effects on year-round water temperatures in temperate zone lakes. Clim Chang 40:547-576

Straile D, Jöhnk K, Rossknecht H (2003) Complex effects of winter warming on the physicochemical characteristics of a deep lake. Limnol Oceanogr 48:1432-1438

Trolle D, Hamilton DP, Pilditch CA, Duggan IC, Jeppesen E (2011) Predicting the effects of climate change on trophic status of three morphologically varying lakes: implications for lake restoration and management. Environ Model Softw 26:354-370 
van Vliet MTH, Ludwig F, Zwolsman JJG, Weedon GP, Kabat P (2011) Global river temperatures and sensitivity to atmospheric warming and changes in river flow. Water Resour Res 47, W02544

Verburg P, Hecky RE (2009) The physics of the warming of Lake Tanganyika by climate change. Limnol Oceanogr 54:2418-2430

Verschuren D (2003) Lake-based climate reconstruction in Africa: progress and challenges. Hydrobiologia 500: 315-330

Weyhenmeyer GA (2008) Water chemical changes along a latitudinal gradient in relation to climate and atmospheric deposition. Clim Chang 88:199-208

Weyhenmeyer GA, Livingstone DM, Meili M, Jensen O, Benson B, Magnuson JJ (2011) Large geographical differences in the sensitivity of ice-covered lakes and rivers in the Northern Hemisphere to temperature changes. Glob Chang Biol 17:268-275

Wilhelm S, Hintze T, Livingstone DM, Adrian R (2006) Long-term response of daily epilimnetic temperature extrema to climate forcing. Can J Fish Aquat Sci 63:2467-2477

Winder M, Schindler DE (2004) Climate change uncouples trophic interactions in an aquatic ecosystem. Ecology $85: 2100-2106$

Winder M, Sommer U (2012) Phytoplankton response to a changing climate. Hydrobiologia 698:5-16

Yokohata T, Emori S, Nozawa T et al (2008) Comparison of equilibrium and transient responses to $\mathrm{CO}_{2}$ increase in eight state-of-the-art climate models. Tellus 60A:946-961 